\title{
Thermoelectric Properties of $\mathrm{CuAl}_{1-x} \mathrm{M}_{x} \mathrm{O}_{2}(\mathrm{M}=\mathrm{Zn}, \mathrm{Ca})$
}

\author{
Takuya Kurotori* and Sunao Sugihara
}

Department of Materials Science and Ceramic Technology Shonan Institute of Technology, Fujisawa 251-8511, Japan

Substitution was performed with $\mathrm{Ca}^{2+}$ and $\mathrm{Zn}^{2+}$ in the $\mathrm{Al}^{3+}$ site of $\mathrm{CuAlO}_{2}$. We investigated the influence of substitution on thermoelectric properties. Power factors were the highest near $850 \mathrm{~K}$ for the samples of $\mathrm{CuAl}_{0.999} \mathrm{Zn}_{0.001} \mathrm{O}_{2}\left(6.8 \times 10^{-5} \mathrm{Wm}^{-1} \mathrm{~K}^{-2}\right)$, $\mathrm{CuAl}_{0.999} \mathrm{Ca}_{0.001} \mathrm{O}_{2}\left(7.4 \times 10^{-5} \mathrm{Wm}^{-1} \mathrm{~K}^{-2}\right), \mathrm{CuAlO}_{2}\left(6.6 \times 10^{-5} \mathrm{Wm}^{-1} \mathrm{~K}^{-2}\right)$.

(Received October 20, 2004; Accepted May 18, 2005; Published July 15, 2005)

Keywords: delafossite, calcium, zinc, copper alminate, seebeck coefficient, electrical conductivity, thermal conductivity, figure of merit

\section{Introduction}

$\mathrm{CuAlO}_{2}$ can be expected to have a high thermoelectromotive force as a thermoelectric material. ${ }^{4,5)}$ However, its electrical conductivity is lower by $1 / 1000$ than that of $\mathrm{NaCO}_{2} \mathrm{O}_{4} \cdot{ }^{1)}$ In order to utilize $\mathrm{CuAlO}_{2}$, as a thermoelectric material it is necessary to improve its electric conductivity, because $\mathrm{Z}\left(=\sigma \alpha^{2} / \kappa\right.$, where $\sigma$ is electrical conductivity, $\alpha$ is Seebeck coefficient, and $\kappa$ is thermal conductivity) is required to have high thermoelectric properties. If $\sigma$ becomes high by this system, thermoelectric efficiency increases.

Result of computer simulation of Yoshida et al. ${ }^{2)}$ showed the Al-vacancy impurity level (acceptor level), where the $\mathrm{Ca}^{2+}$ level was found to be above the Al-vacancy level. The experimental result of Katsui et al. ${ }^{3,6)}$ shows an electrical conductivity which is higher than that of $\mathrm{CuAlO}_{2}$. In this research, polycrystalline $\mathrm{CuAl}_{1-x} \mathrm{M}_{x} \mathrm{O}_{2}(\mathrm{M}=\mathrm{Zn}, \mathrm{Ca})$ was produced based on computer simulations, and we investigated the effects of $\mathrm{Zn}$ and $\mathrm{Ca}$ substitution on its thermoelectric properties.

\section{Experimental Procedures}

$\mathrm{Cu}_{2} \mathrm{O}, \mathrm{Al}_{2} \mathrm{O}_{3}$ and $\mathrm{ZnO} \mathrm{CaCO}_{3}$ powders were used as raw materials for solid-state reaction. ${ }^{6,7)}$ These materials were mixed in a molar ratio of $\mathrm{Al}_{2} \mathrm{O}_{3}:\left(\mathrm{ZnO}, \mathrm{CaCO}_{3}\right)=(1-x): x$ $(x=0,0.001,0.01)$ a planetary ball mill for $2 \mathrm{~h}$. The mixed powders were calcined at $1373 \mathrm{~K}$ for $12 \mathrm{~h}$. Then, $\mathrm{Cu}_{2} \mathrm{O}$ was mixed with the calcined powder, and ball-milled for $24 \mathrm{~h}$, palletized and calcined at $1373 \mathrm{~K}$ for $24 \mathrm{~h}$. The sintered pellet was pulverized. Then it was milled for $24 \mathrm{~h}$. The mixture was obtained at $245(\mathrm{MPa})$ and sintered at $1473 \mathrm{~K}$ for $48 \mathrm{~h}$. The sintered pellet was cut into rectangles and annealed at $1373 \mathrm{~K}$ for $24 \mathrm{~h}$. Electrical conductivity and Seebeck coefficient were measured by the four-probe method, and thermal conductivity was measured by the laser flash method. Microstructures were observed by scanning electron microscopy (SEM) and phase and crystal structures were analyzed by X-ray diffraction (XRD) analysis.

\section{Result and Discussion}

Figure 1 shows the XRD pattern of polycrystalline

*Graduate student, Shonan Institute of Technology

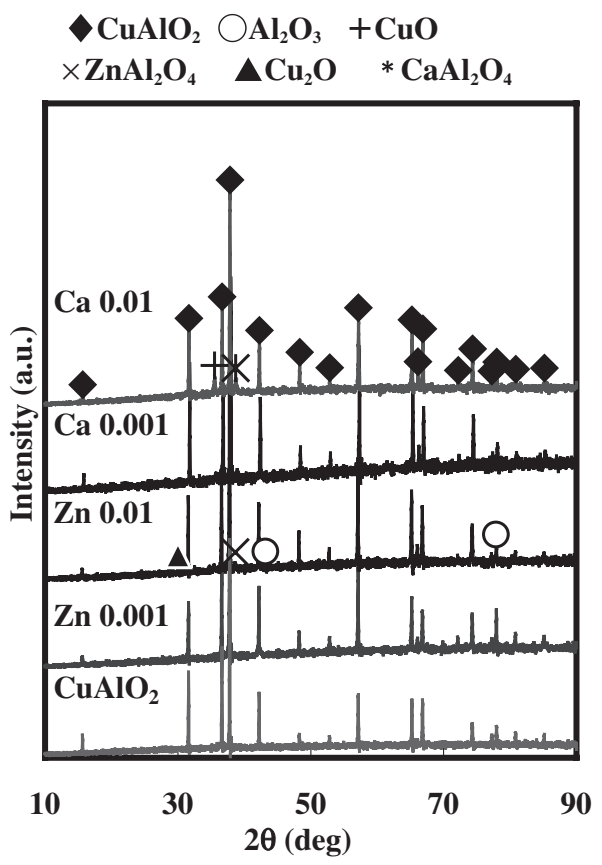

Fig. 1 XRD patterns for sintered $\mathrm{CuAl}_{1-x} \mathrm{M}_{x} \mathrm{O}_{2}(\mathrm{M}=\mathrm{Zn}, \mathrm{Ca})$.

$\mathrm{CuAl}_{1-x} \mathrm{M}_{x} \mathrm{O}_{2}(\mathrm{M}=\mathrm{Zn}, \mathrm{Ca})$. When $\mathrm{Zn}$ and $\mathrm{Ca}$ at $x=0$ and 0.001 were added, single-phase $\mathrm{CuAlO}_{2}$ was obtained. However, the $x=0.01$ for both $\mathrm{Zn}$ and $\mathrm{Ca}$ yielded $\mathrm{CuAlO}_{2}$ with impurity phase. This suggests that the added $\mathrm{Zn}$ and $\mathrm{Ca}$ reacted with $\mathrm{Al}_{2} \mathrm{O}_{3}$ in $\mathrm{ZnAl}_{2} \mathrm{O}_{4}$ and $\mathrm{CaAl}_{2} \mathrm{O}_{4}$, and excess $\mathrm{CuO}$ and $\mathrm{Cu}_{2} \mathrm{O}$ was crystallized as an oxide phase.

Figure 2 shows the lattice parameter dependence of $\mathrm{Zn}$ content $(x)$ for $\mathrm{CuAl}_{1-x} \mathrm{Zn}_{x} \mathrm{O}_{2}$ polycrystalline samples. In Fig. 2(a) the $a$-axis and $c$-axis length dependences of $\mathrm{Zn}$ content $(x)$ are shown. The samples, $a$-axis parameters increase with increasing $\mathrm{Zn}$ content $(x)$. Zn causes the length of the Al-O layer to become shorter because of its stronger ionicity. According to Koumoto et al., ${ }^{4,5)} \alpha_{\|}$indicated the biggest Seebeck coefficient due to the small length between layers. Figure 2(b) shows the $\mathrm{Zn}$ content $(x)$ dependences of $c / a$ and volume, where $c / a$ decreases with $\mathrm{Zn}$ content $(x)$. The reason for the Al-O layer to thin down is suggested to be that $c$-axis length decreases and $a$-axis length increases with Zn content $(x){ }^{14)}$

Figure 3 shows the dependences of $\mathrm{Ca}$ content $(x)$ on 
(a)
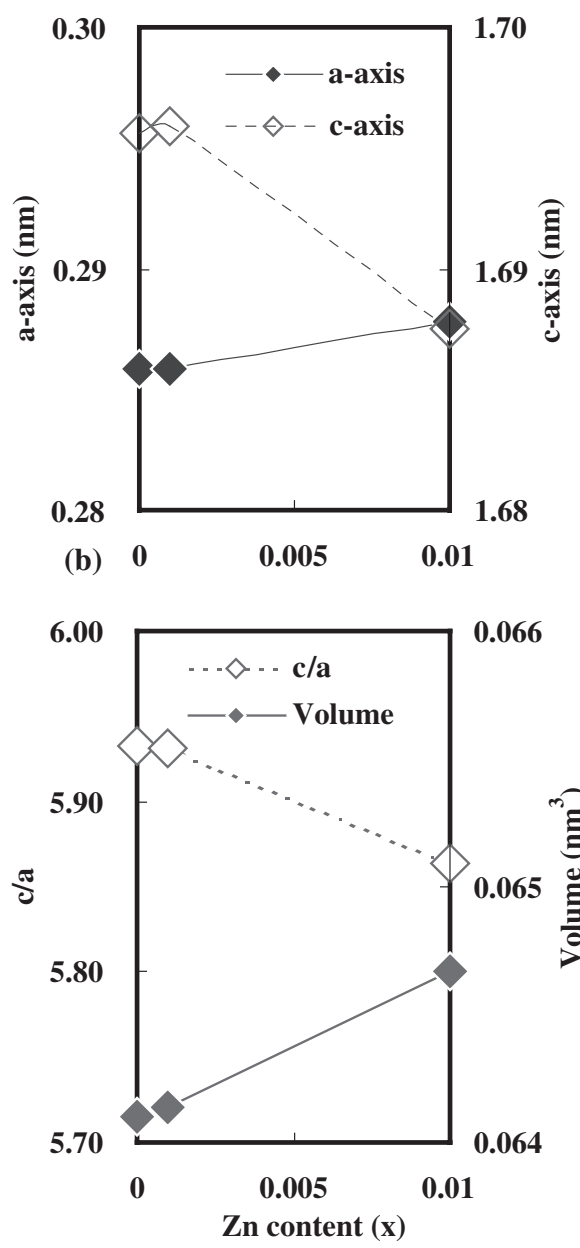

Fig. 2 Lattice parameter of $\mathrm{CuAl}_{1-x} \mathrm{Zn}_{x} \mathrm{O}_{2}$, (a) $a$-axis and $c$-axis, (b) $c / a$ and volume.

lattice parameters for the $\mathrm{CuAl}_{1-x} \mathrm{Ca}_{x} \mathrm{O}_{2}$ polycrystalline samples. Figure 3(a) shows the Ca content $(x)$ dependences of the $a$-axis and $c$-axis. The $a$-axis parameter for $x=0.01$ is larger than that for $x=0.001$. For $x=0.001$, the $c$-axis decreased markedly, but for $x=0.01$ it increased slightly.

Figure 3(b) shows the Ca content $(x)$ dependences of $c / a$ and volume. The $c / a$ for $x=0.01$ was smaller than that for $x=0.001$. For $x=0.001, c / a$ decreased markedly, but for $x=0.001$ it decreased slightly. ${ }^{14)}$

SEM images of the sintered polycrystalline samples shown in Fig. 4. The SEM observations show the damaged surfaces. All the images show platy grains. Zn content $(x)$ increases with increasing grain size. However, Ca content $(x)$ increases with decreasing grain size. The cause of this is suggested to be the poor control of grain growth due to the formation of impurities.

Figure 5 shows the temperature dependence of electrical conductivity of $\mathrm{CuAl}_{1-x} \mathrm{M}_{x} \mathrm{O}_{2}(\mathrm{M}=\mathrm{Zn}, \mathrm{Ca})$ polycrystalline samples. The roughly estimated activation energies $\left(E_{\mathrm{a}}\right)$ at the higher temperature region $(K)$ in the Arrhenius plot $\log \sigma$ vs $1 / T$, were $0.25 \mathrm{eV}$ for $\mathrm{CuAlO}_{2},{ }^{10-12)} \mathrm{Zn} x=0.001,0.01$ and $\mathrm{Ca} x=0.01$. Temperature above $600 \mathrm{~K}$ did not show linearity in the Arrhenius plot $\log \sigma$ vs $1 / T$, this is suggestion (a)
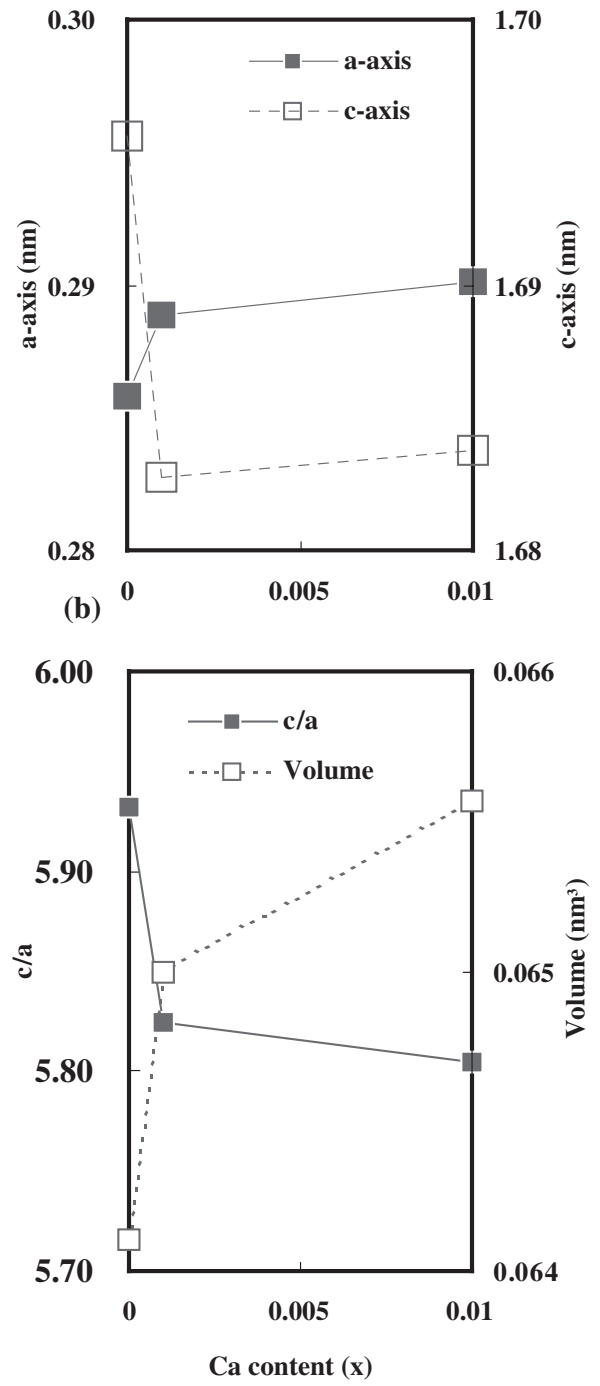

Fig. 3 Lattice parameter of $\mathrm{CuAl}_{1-x} \mathrm{Ca}_{x} \mathrm{O}_{2}$, (a) $a$-axis and $c$-axis, (b) $c / a$ and volume.

influence carrier scattering in the grain boundary. The electrical conductivity $\sigma$ at room temperature is 17.2 $\left(\mathrm{Sm}^{-1}\right)$ for $\mathrm{Ca} x=0.001$, which is the highest $\sigma$ of all samples. There was a difference in electrical conductivity at approximately $500 \mathrm{~K}$ in all samples. However, this difference did not appear at temperatures higher than $500 \mathrm{~K}$. Hole doping was carried out on the samples of Ca $x=0.001$ to increase electrical conductivity. But, following to temperature increase, electrical conductivity had decreased. This is suggested that recombination was caused with electrons where holes are generated in excitation heat. As for all samples, electrical conductivity increases with temperature indicating semiconductor behavior.

Figure 6 shows the temperature dependence of Seebeck coefficient for $\mathrm{CuAl}_{1-x} \mathrm{M}_{x} \mathrm{O}_{2}(\mathrm{M}=\mathrm{Zn}, \mathrm{Ca})$ polycrystalline samples. The Seebeck coefficient $\alpha$ at room temperature is approximately $870\left(\mu \mathrm{VK}^{-1}\right)$ for all samples. As for all samples, with increasing temperature Seebeck coefficient decreased, but at above approximately $650 \mathrm{~K}$ the Seebeck coefficient is negligible. From the fact that the Seebeck 


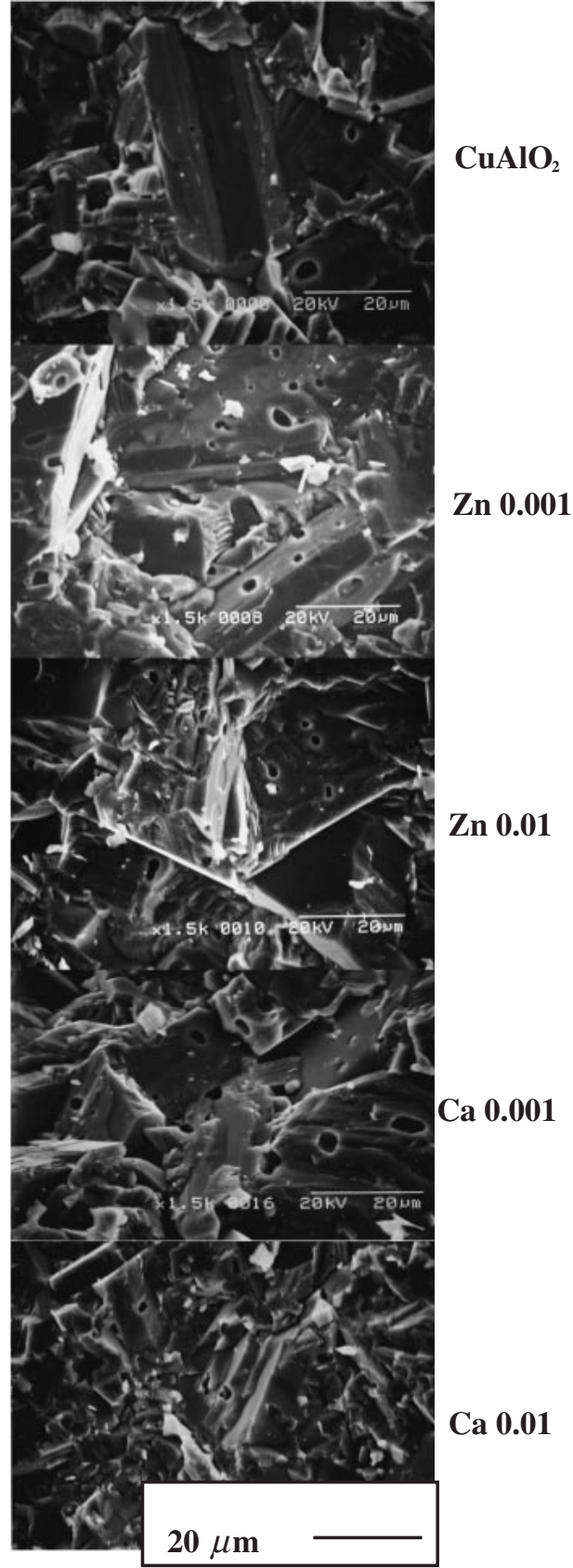

Fig. 4 SEM images of sintered $\mathrm{CuAl}_{1-x} \mathrm{M}_{x} \mathrm{O}_{2}(\mathrm{M}=\mathrm{Zn}$ and Ca) polycrystalline samples.

coefficient is positive, all samples are p-type semiconductors.

Figure 7 shows the temperature dependence of thermal conductivity for $\mathrm{CuAl}_{1-x} \mathrm{M}_{x} \mathrm{O}_{2}$ ( $\left.\mathrm{Zn}, \mathrm{Ca}\right)$ polycrystalline samples. The thermal conductivity $\kappa$ of $\mathrm{Zn} x=0.01$ at room temperature is approximately 10 times that of conventional oxides. Following to temperature increase it decreased thermal conductivity. For $\mathrm{Zn} x=0.001$, the thermal conductivity of approximately $5\left(\mathrm{Wm}^{-1} \mathrm{~K}^{-1}\right)$ as the lowest in all samples. Thermal conductivity increased with $\mathrm{Zn}$ content based on the grain size as shown in the SEM image in Fig. 4. $\mathrm{Zn} x=0.01$. Also, the fact that it increased with increasing amount of impurities is the cause of $\mathrm{Zn} x=0.01$ according to XRD analysis. Even in the case of $\mathrm{Ca} x=0.01$, the existence of the impurities was verified by the decrease in thermal

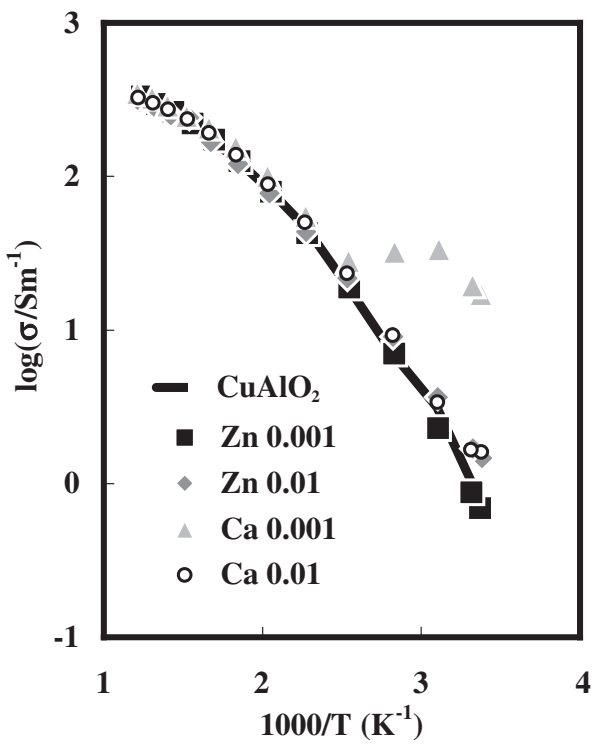

Fig. 5 Temperature dependence of electrical conductivity $(\sigma)$ of sintered $\mathrm{CuAl}_{1-x} \mathrm{M}_{x} \mathrm{O}_{2}(\mathrm{M}=\mathrm{Zn}, \mathrm{Ca})$ polycrystalline samples.

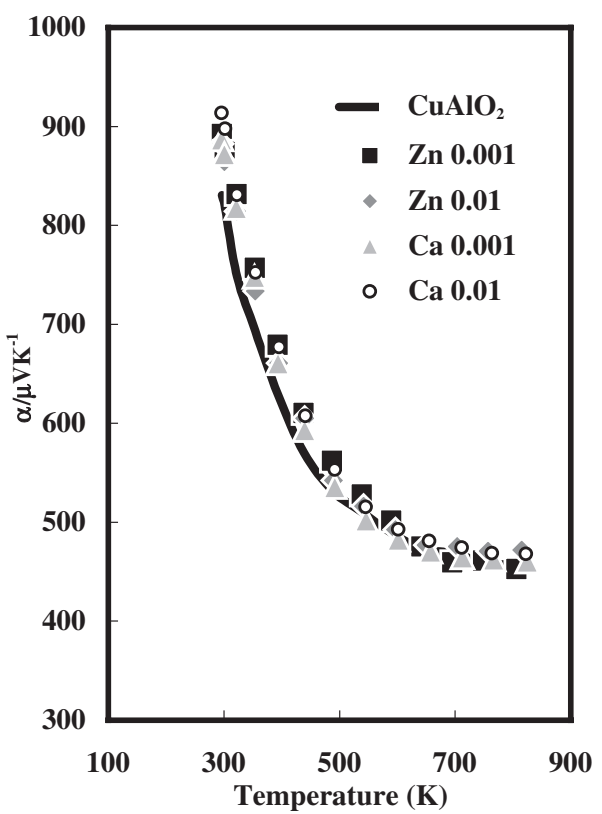

Fig. 6 Temperature dependence of Seebeck coefficient $(\alpha)$ of sintered $\mathrm{CuAl}_{1-x} \mathrm{M}_{x} \mathrm{O}_{2}(\mathrm{M}=\mathrm{Zn}, \mathrm{Ca})$ polycrystalline samples.

conductivity with increasing temperature. The reason the $\mathrm{Zn}=0.01$ sample had a larger $\kappa$ was suggested to be that there might exist impurities such as $\mathrm{ZnAl}_{2} \mathrm{O}_{4}\left(25 \mathrm{Wm}^{-1} \mathrm{~K}^{-1}\right.$ $300 \mathrm{~K})$ possessing a larger thermal conductivity. $\left.{ }^{9}\right)$ Furthermore, the case of $\mathrm{Zn}=0.001$ showed the lowest $\kappa$ and one forth that of the case of $\mathrm{Zn}=0.01$ at $400 \mathrm{~K}$. In addition, $\kappa$ for $\mathrm{Zn}=0.001$ decreased with increasing temperature up to $850 \mathrm{~K}$. We found the optimum amount of $\mathrm{Zn}$ required to decrease $\kappa$, which was not regarded to form $\mathrm{ZnO}$. This is the main difference between $\mathrm{Zn}$ and $\mathrm{Ca}$.

The figures of merits of the samples of $\mathrm{CuAl}_{1-x} \mathrm{M}_{x} \mathrm{O}_{2}$ $(\mathrm{M}=\mathrm{Zn}, \mathrm{Ca})$ are shown in Fig. 8. The largest one in the case of $\mathrm{Zn}=0.001$ was $1.3 \times 10^{-5} \mathrm{~K}^{-1}$ at approximately $850 \mathrm{~K}$, 


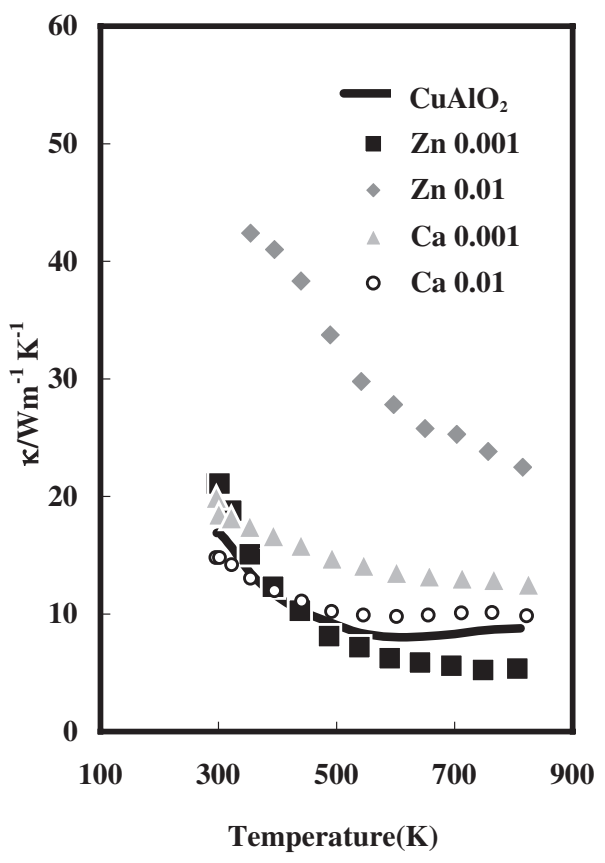

Fig. 7 Temperature dependence of thermal conductivity $(\kappa)$ of sintered $\mathrm{CuAl}_{1-x} \mathrm{M}_{x} \mathrm{O}_{2}(\mathrm{M}=\mathrm{Zn}, \mathrm{Ca})$ polycrystalline samples.

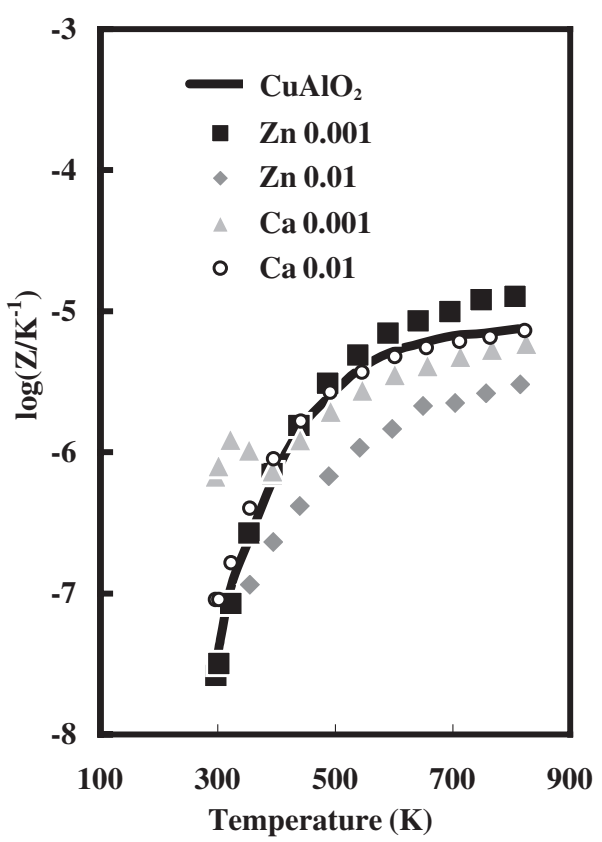

Fig. 8 Temperature dependence of figure of merit (Z) of sintered $\mathrm{CuAl}_{1-x} \mathrm{M}_{x} \mathrm{O}_{2}(\mathrm{M}=\mathrm{Zn}, \mathrm{Ca})$ polycrystalline samples. which was only one order larger than that in the case of $\mathrm{CuAlO}_{2}$. These of figures of merit were 10 times larger than those of the other oxide because of the larger thermal conductivity. The power factors, PFs, at approximately $850 \mathrm{~K}$ are $x=0 ; 6.6 \times 10^{-5}$, Zn $x=0.001 ; 6.8 \times 10^{-5}, \mathrm{Zn} x=$ $0.01 ; 6.8 \times 10^{-5}$, Ca $x=0.001 ; 7.4 \times 10^{-5}$, Ca $x=0.01$; $7.2 \times 10^{-5}\left(\mathrm{Wm}^{-1} \mathrm{~K}^{-2}\right)$.

\section{Conclusion}

The electrical conductivities of the substituted samples ( $\mathrm{Zn}$ and $\mathrm{Ca}$ ) were almost the same. Even in terms of temperature dependence and did not improve compared with the $\mathrm{CuAlO}_{2}$. However, the sample of $\mathrm{Zn}=0.001$ had a decreased thermal conductivity of $5\left(\mathrm{Wm}^{-1} \mathrm{~K}^{-1}\right)$ at approximately $800 \mathrm{~K}$, which showed a decrease in $\mathrm{CuAl}_{0.999} \mathrm{Zn}_{0.001} \mathrm{O}_{2}$ with increasing temperature. The resulting figure of merit was $1.3 \times 10^{-5}$ $\left(\mathrm{K}^{-1}\right)$. This figure of merit is approximately 1.7 times better than the $7.5 \times 10^{-6}\left(\mathrm{~K}^{-1}\right)$ of $\mathrm{CuAlO}_{2}$.

\section{REFERENCES}

1) M. Ohtaki: Metal. 68 (1998) 1101-1109 (in Japanese).

2) H. Katayama-Yoshida, T. Koyanagi, H. Funashima, H. Harima and A. Yanase: Solid State Commun. 126 (2003) 135-139.

3) A. Katsui, J. Yoshizawa and H. Matsusita: Proceeding Thermoelectric Conversion Symposium (Thermoelectric Conversion Research Committee of Japan, 2002) 160-161 (in Japanese).

4) K. Koumoto, H. Koduka and W. S. Seo: Proceeding of 19th International Conference on Thermoelectrics (International Thermoelectric Society, 2000) 232-235.

5) K. Koumoto, H. Koduka and W. S. Seo: J. Mater. Chem. 11 (2001) 251-252.

6) A. Katsui, J. Yoshizawa and H. Matsusita: J. Jpn. Soc. Powder Powder Metall. 50 (2003) 670-673.

7) H. Yanagi, S. Inoue, K. Ueda, H. Kawazoe, H. Hosono and N. Hamada: J. Appl. Phys. 88 (2000) 4159-4163.

8) D. Y. Shahriari, A. Barnabe, T. O. Mason and K. R. Poeppelmeier: Inorg. Chem. 40 (2001) 5734-5735.

9) Y. Yoshida, T. Kurotori, S. Hiki, H. Yano and S. Sugihara: Proceeding of Annual Meeting of the Termoelectrics Society Japan (The Thermoelectrics Society of Japan, 2004) 136-137 (in Japanese).

10) X. Nie, S. H. Wei and S. B. Zhang: Phys. Rev. Lett. 88 (2002) 066405$1,4$.

11) B. J. Ingram, T. O. Mason, R. Asahi, K. T. Park and A. J. Freeman: Phys. Rev. B. 64 (2001) 155114-1, 7.

12) H. Kawazoe, M. Yasukawa, H. Hyoudo, M. Kurita, H. Yanagi and H. Hosono: Nature 389 (1997) 939.

13) H. Kawazoe, H. Yanagi, K. Ueda and H. Hosono: MRSBULLETIN/ AUG 25 (2000) 28-36.

14) K. Isawa, Y. Yaegashi, S. Ogata, M. Nagano and S. Sudo: Phys. Rev. B 57 (1998) 137950. 